\title{
Synthesis and Characterization of Metal Organic Chemical Vapour Deposited Chromium Doped Zinc Oxide Thin Film for Gas Sensing Applications
}

\author{
Olumide Oluwole Akinwunmi ${ }^{*}$, Olakunle A. Akinwumi ${ }^{1}$, Johnson Ayodele 0. Ogundeji ${ }^{1}$, \\ Adetokunbo Temitope Famojuro²
}

${ }^{1}$ Department of Physics and Engineering Physics, Obafemi Awolowo University, Ile-Ife, Nigeria

${ }^{2}$ Department of Chemistry, Obafemi Awolowo University, Ile-Ife, Nigeria

Email: *oakinwunmi@oauife.edu.ng, ooakinwunmi@gmail.com

How to cite this paper: Akinwunmi, O.O., Akinwumi, O.A., Ogundeji, J.A.O. and Famojuro, A.T. (2018) Synthesis and Characterization of Metal Organic Chemical Vapour Deposited Chromium Doped Zinc Oxide Thin Film for Gas Sensing Applications. Materials Sciences and Applications, 9, 844-857.

https://doi.org/10.4236/msa.2018.910061

Received: August 30, 2018

Accepted: September 26, 2018

Published: September 29, 2018

Copyright $\odot 2018$ by authors and Scientific Research Publishing Inc. This work is licensed under the Creative Commons Attribution International License (CC BY 4.0).

http://creativecommons.org/licenses/by/4.0/

(c) $\underset{\mathrm{EY}}{\mathrm{B}}$ Open Access

\begin{abstract}
Chromium ( $\mathrm{Cr}$ ) doped Zinc oxide $\mathrm{ZnO}$ thin films were deposited onto glass substrates by Metal Organic Chemical Vapour Deposition (MOCVD) technique with varying dopant concentration at a temperature of $420^{\circ} \mathrm{C}$. The effect of the chromium concentration on morphological, structural, optical, electrical and gas sensing properties of the films were investigated. The scanning electron microscopy results revealed that the $\mathrm{Cr}$ concentration has great influence on the crystallinity, surface smoothness and grain size. X-ray diffraction (XRD) studies shows that films were polycrystalline in nature and grown as a hexagonal wurtzite structure. A direct optical band energy gap of 3.32 to $3.10 \mathrm{eV}$ was obtained from the optical measurements. The transmission was found to decrease with increasing $\mathrm{Cr}$ doping concentration. Rutherford Backscattering Spectroscopy (RBS) analysis also demonstrates that $\mathrm{Cr}$ ions are substitutionally incorporated into $\mathrm{ZnO}$. I-V characteristic of the film shows a resistivity ranges from $1.134 \times 10^{-2} \Omega \mathrm{cm}$ to $1.24 \times 10^{-2} \Omega \mathrm{cm}$ at room temperature. The gas sensing response of the films were enhanced with incorporation of $\mathrm{Cr}$ as a dopant with optimum operating temperature around $200^{\circ} \mathrm{C}$.
\end{abstract}

\section{Keywords}

Zinc Oxide, Thin Films, Metal Organic Chemical Vapour Deposition, Gas Sensors

\section{Introduction}

$\mathrm{ZnO}$ has been found invaluable in the development of new technologies based 
on the physical characteristics that, under good deposition conditions, are attractive for a wide variety of scientific applications in different electronics devices, such as gas sensors [1], ultraviolet light emitting devices, transparent conducting films and solar cell [2] [3] gamma radiation sensing layers [4], and pressure sensors [5]. In thin film form, high transparency is observed in the uv-visible region; however, its metallic properties lead to a reflectance in the infrared spectrum couple with high conductivity [6]. The characteristic wide band gap and large exciton binding energy $(60 \mathrm{meV})$ makes $\mathrm{ZnO}$ importantly attractive, in addition to their low cost and non-toxicity.

The energy level, surface state and transport performance of carriers in semiconductor can be altered in other to enhance their properties for potential application in optoelectronic devices by doping with appropriate element [7] [8] [9]. The use of transition element has been one of effective ways of enhancing the bandgap of $\mathrm{ZnO}$ [10]. The doping efficiency depends on the relative difference in ionic radius and electronegativity between the host and dopant element. $\mathrm{Cr}$ is a member of the transition element with close ionic radius $\left(\mathrm{Cr}^{3+}: 0.62 \AA\right.$, $\mathrm{Zn}^{2+}: 0.74 \AA$ ) and electronegativity (1.66 and 1.65) with $\mathrm{Zn}$. Therefore, $\mathrm{Cr}^{3+}$ can effectively substitute into $\mathrm{ZnO}$ lattice. The tailoring of optical band gap of $\mathrm{ZnO}$ with $\mathrm{Cr}$ as a dopant can be applied in the detectors and light emitters [11]. Cr doped $\mathrm{ZnO}$ thin films are known to be chemically stable against etching and exhibit a wide range of magnetic properties including room temperature ferromagnetism which can be applied to short-wave magneto-optical devices [11] [12].

$\mathrm{Cr}$ doped $\mathrm{ZnO}$ thin films can be prepared by many techniques such as sol-gel [13], RF magnetron sputtering, co-sputtering [14] [15] [16] and pulse laser deposition [17] electron beam (e-beam) technique [18]. In most of these deposition techniques, controlling the experimental parameter to achieve co-doped films has a major challenge.

In this work $\mathrm{Cr}$ doped $\mathrm{ZnO}$ thin films were deposited on soda lime glass by Metal Organic Chemical Vapour Deposition (MOCVD) using a single solid precursor. Though less sophisticated when compared with other techniques, it has large-area to volume and conformal deposition capability and close to ambient deposition temperature. The effect of $\mathrm{Cr}$ concentrations on the gas sensing properties of doped $\mathrm{ZnO}$ using ammonium as gas is also reported. The prepared precursors were characterized using Fourier Transform Infrared (FTIR) spectroscopy while the thin films' properties were characterized using Field Emission Scanning Electron Microscopy (FE-SEM), X-ray diffractometer, Ultraviolet-Visible (UV-Vis) Spectroscopy, Rutherford Backscattering Spectroscopy (RBS) and Four Point Probe technique.

\section{Experimental}

\subsection{Materials}

Chromium (III) acetylacetonate, acetone and methanol were reagents obtained 
from Sigma-Aldrich while Zinc acetate dihydrate $\left(\mathrm{Zn}\left(\mathrm{CH}_{3} \mathrm{COO}\right)_{2} \cdot 2 \mathrm{H}_{2} \mathrm{O}\right)$ was obtained from Fisher Scientific. All reagents were used without further purification.

\subsection{Preparation of Precursor}

The single solid source precursor was prepared from the mixture of Zinc acetate dihydrate and chromium acetylacetonate. Zinc acetate $(0.05 \mathrm{M})$ was dissolved and stirred vigorously with a magnetic stirrer in a mix of water, acetone, and methanol at $25^{\circ} \mathrm{C}$. A $0.05 \mathrm{M}$ prepared solution of chromium acetylacetonate in acetone was used as doping source, introduced based on stoichiometry, such that the ratio of atomic concentration of $\mathrm{Cr}$ with respect to $\mathrm{Zn}$ were $1,2,3$ and 5 at\%. [11]. The resulting solution was oven dried to constant weight at $60^{\circ} \mathrm{C}$ and pulverized before pyrolysis.

\subsection{Film Deposition}

The thin films were deposited at $420^{\circ} \mathrm{C}$ on a soda lime glass substrate with nitrogen gas as a carrier gas with a flow of $2.5 \mathrm{dm}^{3} / \mathrm{min}$ (Figure 1). The soda-lime substrates were mounted on stainless steel blocks within the heating chamber to ensure effective thermal contact. The time of deposition was two hours.

\subsection{Characterization of the Precursor and Films}

\subsubsection{Fourier Transform Infrared (FTIR) Spectroscopy}

The FT-IR spectrum of the precursors (doped and un-doped) were recorded on a Perkin Elmer Spectrum 100 FTIR spectrometer.

\subsubsection{Electron Microscopy}

The morphological micrographs of the $\mathrm{Cr}: \mathrm{ZnO}$ thin films were obtained using a Zeiss Plus 55 FE-SEM.

\subsubsection{Powder X-Ray Diffraction}

The crystal structure was investigated by PANalytical X'Pert Pro Multi-purpose Diffractometer (MPD). The diffractometer is a Philips PW3040/60 X-ray generator, fitted with an X'Celerator detector. Diffraction data were acquired by exposing the thin film to $\mathrm{Cu}-\mathrm{K}_{\alpha} \mathrm{X}$-ray radiation $(\lambda=1.5418 \AA$ ). X-rays were generated from a Cu anode supplied with $40 \mathrm{kV}$ and a current of $40 \mathrm{~mA}$.

\subsubsection{Optical Properties}

Transmittance spectra of the thin films were measured with Shimadzu UV-Vis 1800 double beam spectrophotometer in the wavelength range $400-800 \mathrm{~nm}$.

\subsubsection{RBS Spectrum}

The elemental composition, stoichiometry, thickness and depth profile of the film were acquired using Rutherford Backscattering Spectroscopy. The samples were analyzed using National Electrostatic Corporation's (NEC) 1.7 MV Tandem Accelerator with $2 \mathrm{MeV} \mathrm{He}{ }^{++}$(mass = 4) nuclides as the ion beam and 
$0.3 \mu \mathrm{C}$. The spectrum was obtained under normal condition (angle of incidence $\theta_{1}=0$ and angle of emergence $\theta_{2}=180^{\circ}$ ). The beam current was less than $15 \mathrm{nA}$ with nominal beam size of $1 \mathrm{~mm}$. Depth profile and compositional analysis of the thin film was extracted with RBS spectrum using the SIMNRA and RUMP software.

\subsubsection{Electrical Properties}

The electrical properties of the films were investigated using a Jandel four point probes technique (model TY242MP) and a Keithly 2636 A dual channel source/measurement equipment. The studies were carried out at room temperature within the voltage sweep of $0-0.5 \mathrm{~V}$.

\subsubsection{Gas Sensing}

The gas sensing characteristics of the thin film were carried out using a homemade laboratory system. The system operates on the principle that, there must be change in resistivity of the film with respect to change in gas concentration (ammonium) and as well as operating temperature. The temperature of $\mathrm{Cr}$ doped $\mathrm{ZnO}$ thin films varies in value from room temperature $\left(27^{\circ} \mathrm{C}\right)$, to $350^{\circ} \mathrm{C}$ while ammonium concentration was maintained at $700 \mathrm{ppm}$.

\section{Result and Discussion}

\subsection{Precursor}

The FTIR spectrum of the precursor, undoped and doped is shown in Figure 2(a) and Figure 2(b). The spectrum show that the basic absorption bands are between 4000 and $450 \mathrm{~cm}^{-1}$. The major peaks are: $\mathrm{OH}$ stretching or $\mathrm{M}-\mathrm{OH}-\mathrm{M}$ band in range of $3400-3500 \mathrm{~cm}^{-1}$, C-H vibration in range of $2922-2852 \mathrm{~cm}^{-1}$, carbonyl stretching $(\mathrm{C}=\mathrm{O})$ at $1542 \mathrm{~cm}^{-1}$, C-C stretching at $1200,11001002 \mathrm{~cm}^{-1}$ and $\mathrm{M}-\mathrm{O}$ band at below $1000 \mathrm{~cm}^{-1}$. The bands for $\mathrm{C}-\mathrm{C}$ stretching and bending shifted to the lower frequencies in the case of $\mathrm{Cr}$ doping. This shows that the $\mathrm{Zn}-\mathrm{O}$ bond has been altered due to $\mathrm{Cr}$ doping. The peaks in the range of $428-688 \mathrm{~cm}^{-1}$ correspond to the $\mathrm{Zn}-\mathrm{O}$ bond stretching. The bands observed at $790 \mathrm{~cm}^{-1}$ could be attributed to $\mathrm{Cr}-\mathrm{O}$ bond stretching.

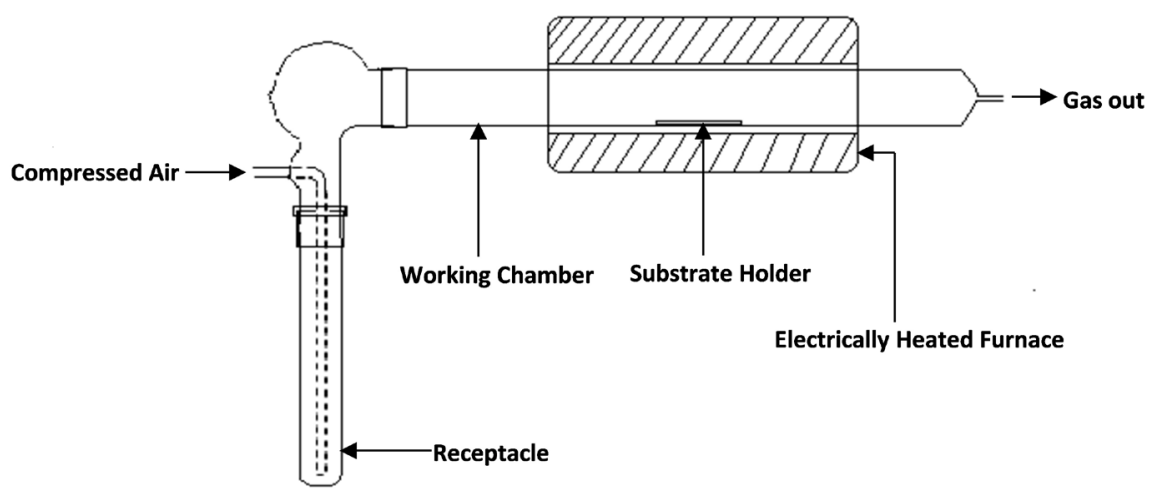

Figure 1. Cross section of the film deposition working chamber. 


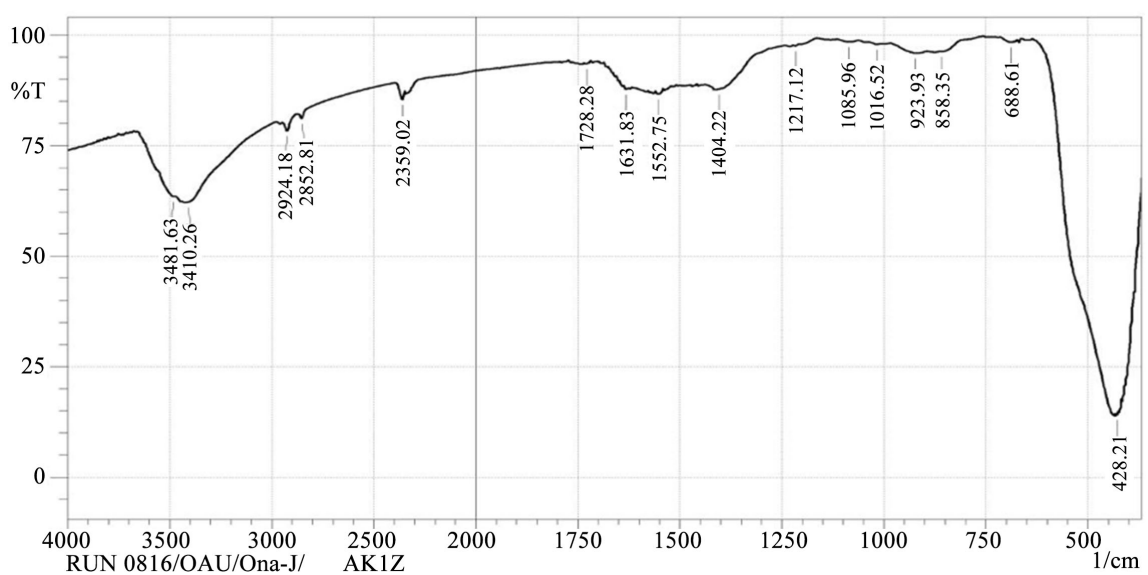

(a)

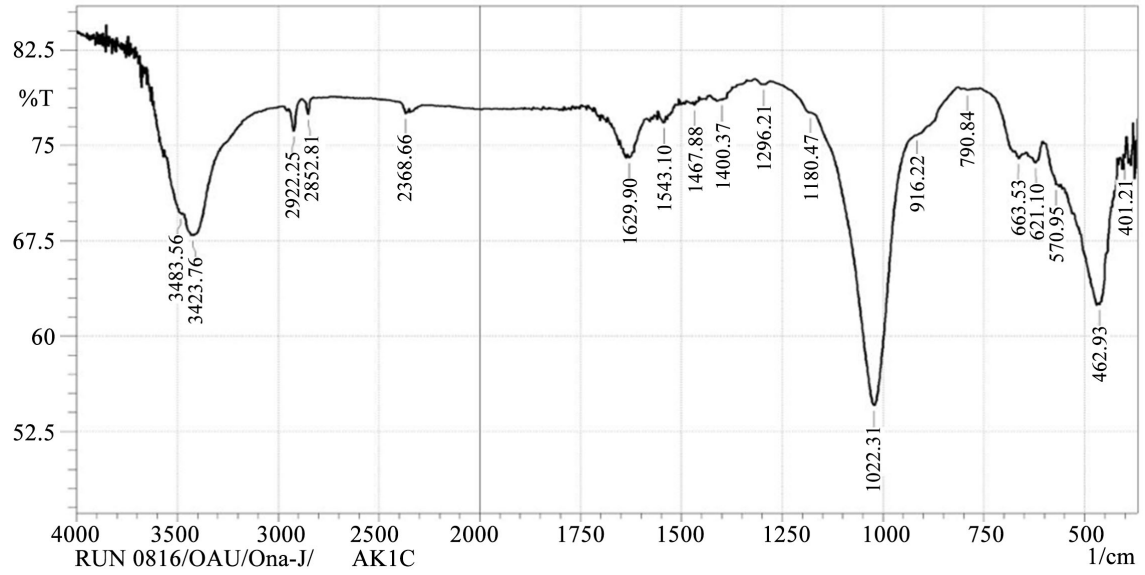

(b)

Figure 2. FTIR spectrum of the thin film precursor (a) undoped zinc oxide (b) $3 \% \mathrm{Cr}$ doped $\mathrm{ZnO}$.

\subsection{Surface Morphology}

The SEM micrographs of the $\mathrm{ZnO}$ thin films deposited at $420^{\circ} \mathrm{C}$ as a function of the $\mathrm{Cr}$ content were shown in Figures 3(a)-(e). The surface morphological studies shows the formation of clusters like structure of undoped $\mathrm{ZnO}$ while with addition of $\mathrm{Cr}$, the film showed the crystalline grains on the surface. It also reveals that the $\mathrm{Cr}$ concentration has great influence on the crystallinity and grain size. As the doping concentration increases, the films surface is smooth and the grains are uniform with agglomerated secondary grains, which are rounded in shape and compactly stacked up. Further increase in dopant concentration results in a compact leave-like structure. The primary grain size decreases as the $\mathrm{Cr}$ concentration increases. It was observed that the grain size is in the order of 125,100 , and $80 \mathrm{~nm}$, respectively for films deposited with $1 \%, 3 \%$ and $5 \% \mathrm{Cr}$ dopant. This shows that as dopants concentrations increases, the film surface compactness also increases.

The relative smoothness of the surface and variation in the grain size which is comparable to the previous work reported by Aguilar-Leyva et al. (2007) [19] 


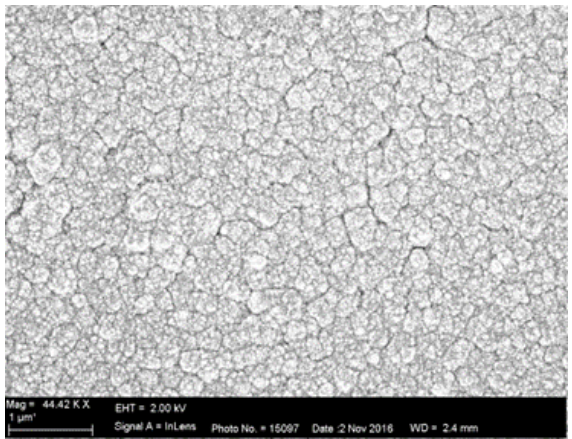

(a)

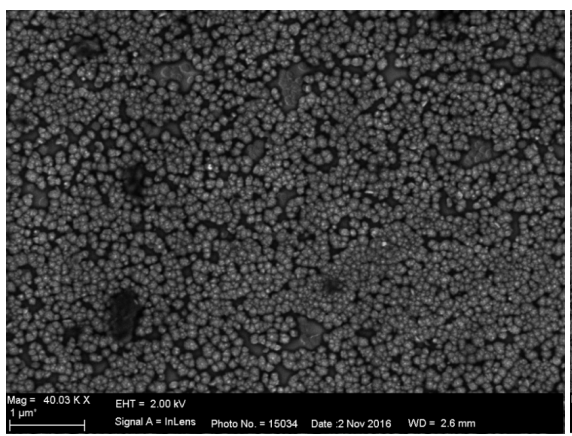

(c)

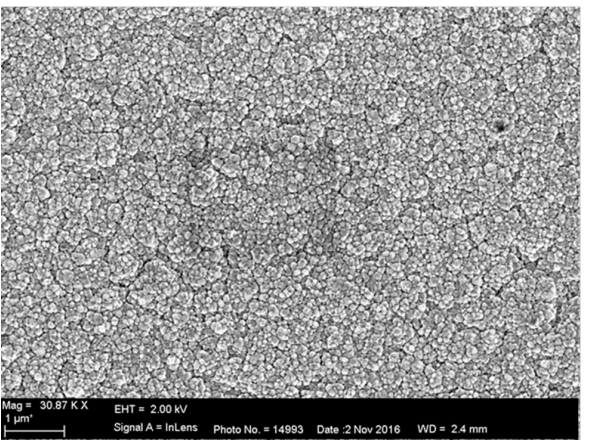

(b)

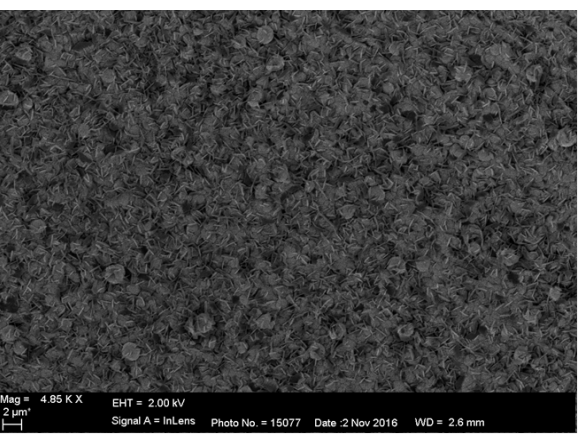

(d)

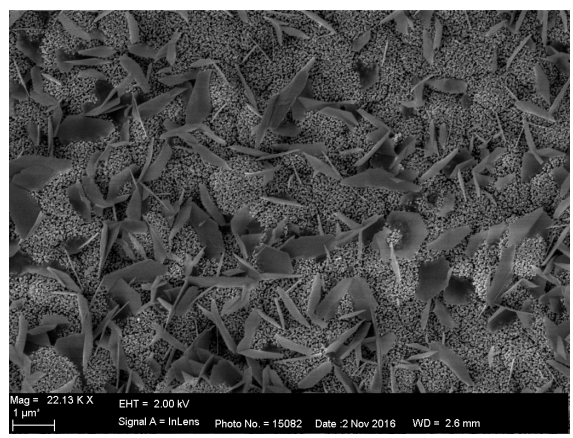

(e)

Figure 3. SEM images of (a) pure $\mathrm{ZnO}$, (b) 1.0 at\% $\mathrm{Cr}$, (c) 2.0 at $\% \mathrm{Cr}$, (d) 3.0 at\% $\mathrm{Cr}$ and (e) 5.0 at\% $\mathrm{Cr}$ doped $\mathrm{ZnO}$ thin films.

may be due to the effect of the acetone used as solvent in order to improve the crystallization [20] [21]. This may also affect the sensing properties.

\subsection{Structural Properties}

Figure 4 shows the $\mathrm{X}$-ray diffraction patterns of as deposited $\mathrm{ZnO}$ thin films as a function of $\mathrm{Cr}$ dopant concentration in solution. This pattern agreed well with the JCPDS standard (No. 36 - 1451) data of hexagonal wurtzite structured $\mathrm{ZnO}$ bulk powder.

The films were polycrystalline in nature with indexed diffractions peaks corresponding to (100), (002), (101) and (110) lattice planes. Diffraction peak of (002) plane were observed for all the deposited thin film irrespective of their doping concentration having preferential crystalline orientation along the c-axis; 
(002) plane. The common intensity peak (002) in all the spectra shows that the quality of the films are good [19] [22]. The peaks belonging to Cr metal, oxides or any other impurity were absent, indicating a complete substitution of Cr metal in host compound ( $\mathrm{ZnO}$ ). Jayaraman et al. (2017) [23] have reported similar phenomenon in doped $\mathrm{ZnO}$. Full width at half maximum (FWHM) varies with dopants concentration, resulting in variation in the average crystallite size (thickness). The average crystallite size was determined using Debye Scherrer's formula and found to be 85, 125, 110100 and $80 \mathrm{~nm}$ for $\mathrm{ZnO}$ film with $0 \%, 1 \%$, $2 \%, 3 \%$ and $5 \% \mathrm{Cr}$ as dopant respectively. This implies that there is an initial increase in grain size with addition of $\mathrm{Cr}$ and subsequently decrease in the grain size with increase in $\mathrm{Cr}$ content.

\subsection{Optical Properties}

The optical band gap energy (Eg) was determined from transmission measurements by analyzing the optical data with the expression for the optical absorption coefficient.

The effect of increasing $\mathrm{Cr}$ dopant concentration on the optical transmittance of the $\mathrm{ZnO}$ thin films are shown in Figure 5(a). Generally the transmission decreases with increase in $\mathrm{Cr}$ concentration. Similar observation had been reported by Amjid Iqbal et al. (2013) [18]. This effect may be due to the thickness of the films and doping effect. The observed decrease in the optical band gap in transition metal doped II-IV semiconductor compounds may be explain in terms of sp-d spin exchange interaction between the localized d electrons of substituting the cations (transition metal ions) and band electrons [24] [25].

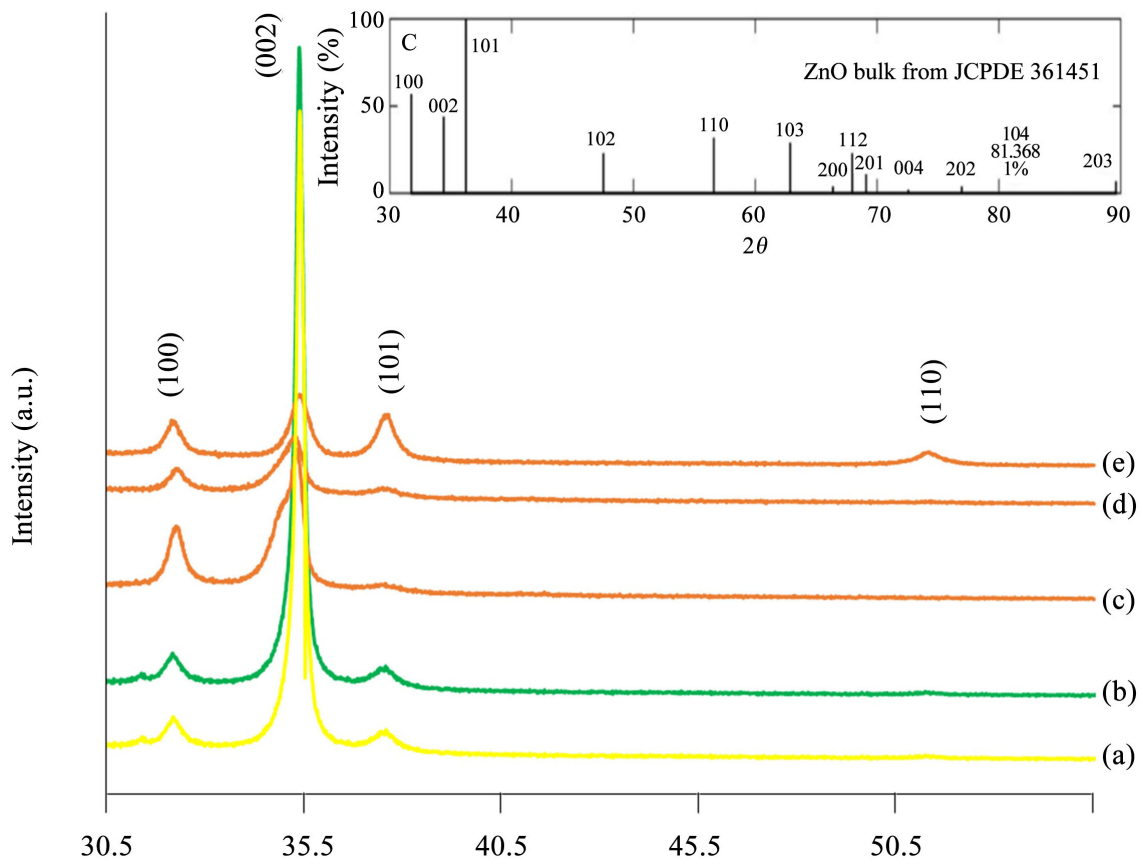

Figure 4. XRD pattern of (a) pure $\mathrm{ZnO}$, (b) 1.0 at\% Cr, (c) 2.0 at\% $\mathrm{Cr}$, (d) 3.0 at $\% \mathrm{Cr}$ and (e) 5.0 at\% $\mathrm{Cr}$ doped $\mathrm{ZnO}$ thin films. 


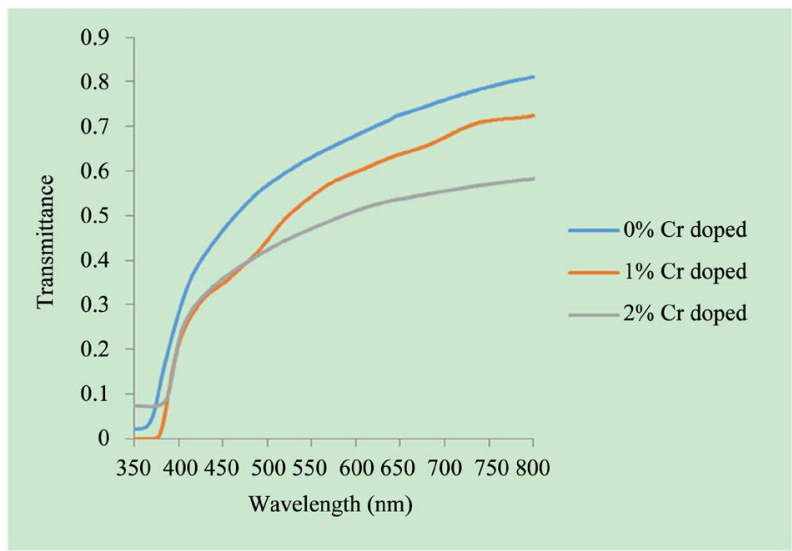

(a)

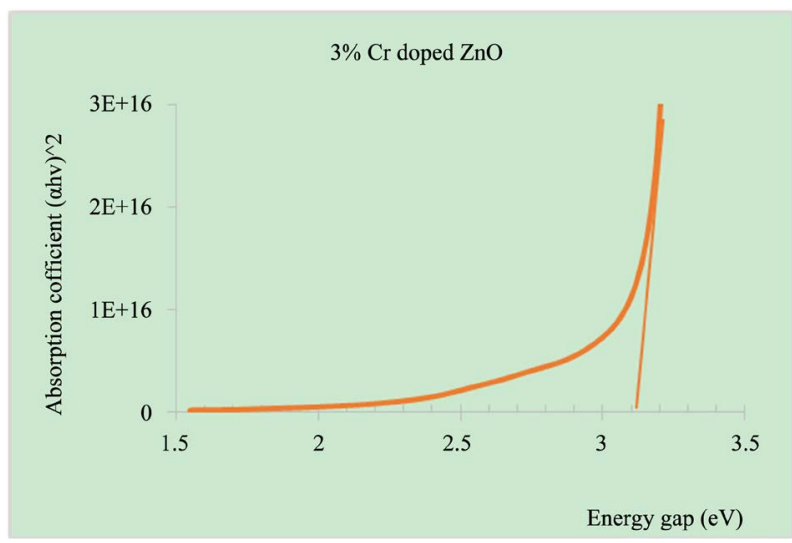

(b)

Figure 5. (a) Transmittance spectra of pure $\mathrm{ZnO}, 1.0$ at\% $\mathrm{Cr}$, and 2.0 at\% $\mathrm{Cr}$, doped $\mathrm{ZnO}$ thin films. (b) Square of $(\alpha \mathrm{h} v)$ absorption coefficient vs photon energy for the thin film.

The absorption coefficient $(\alpha)$ is calculated from the relationship;

$$
\alpha=\frac{1}{d} \ln \frac{1}{T}
$$

where $d$ is the thickness of the film and $T$ is the transmittance. For a direct band gap material, the absorption coefficient is related to the energy of the photon by the expression as follows;

$$
(\alpha h v)^{2}=K\left(h v-E_{g}\right)
$$

where $K$ is a constant of proportionality, $h v$ is the energy of the photon and $E_{g}$ is the band energy.

The absorption coefficient $\alpha$ was determined using Equation (1) while band gap of the films were obtained from the extrapolation of the linear portion of the graph of $(\alpha \mathrm{h} v)^{2}$ versus $E_{g}$ to $\alpha=0$. The optical band gap of the undoped $\mathrm{ZnO}$ was found to be $3.32 \mathrm{eV}$ while that of doped $\mathrm{ZnO}$ ranges from $3.32 \mathrm{eV}$ to $3.10 \mathrm{eV}$ (Figure 5(b)) [24] [26].

\subsection{Composition and Depth Profile}

The SIMNTRA software was used to fit the RBS data with elemental profiles. 
The depth profiles of the blank substrate, undoped and doped thin films, and as well as RBS spectra of the film were shown in Figures 6(a)-(d), and Figure 7 (a) and Figure 7 (b) respectively. The depth profile of the films though semi-quantitative, shows a constant bulk concentration of $\mathrm{Zn}, \mathrm{O}$ and $\mathrm{Cr}$ throughout the thin films along with an estimated ratio of the thickness of the thin films to that of the substrate. While depth profile of blank substrate reveals that silicon (si) and oxygen (O) are the major constituent with oxygen having a concentration $83.66 \mathrm{~atm} \%$. (Figure 6(a)). The depth profile of the films $(0 \%$, $3 \%$ and 5\% Cr doped) shown in Figures 6(b)-(d) reveal almost constant elemental concentration of oxygen in all the deposited films and a constant reduction of $\mathrm{O}$ concentration to 70.05 at $\%$ in the substrate layer. The reduction of $\mathrm{O}$ concentration from 84.66 to 70.05 at\% shows that there is a diffusion of $\mathrm{O}$ from the substrate layer into the deposited film layers which may result in an out-diffusion effect [27]. This may be due to deposition temperature. Hence, O contribution from the precursor to the stoichiometry of both doped and undoped $\mathrm{ZnO}$ is greatly masked by the diffused $\mathrm{O}$ from the substrate. The thickness of the film is estimated to range from 101 to $150 \mathrm{~nm}$ as obtained from the RBS spectrum. The fit in Figure (4b) gives a stoichiometry of $\mathrm{Zn}: \mathrm{Cr}: \mathrm{O}$ to be 53:24:45.

\subsection{Electrical Properties}

The I-V characteristic curves are shown in figures in Figure 8(a) and Figure 8 (b). The figure reveal that the I- $\mathrm{V}$ curves are linear for all the doped and undoped thin films with resistivity ranging from $1.134 \times 10^{-2} \Omega \mathrm{cm}$ to $1.24 \times 10^{2} \Omega$ $\mathrm{cm}$ at $300 \mathrm{~K}$. The resistivity is observed to decrease with increase in $\mathrm{Cr}$ doping concentration up till 3\% $\mathrm{Cr}$ doped. Further increase in $\mathrm{Cr}$ concentration at 5\% $\mathrm{Cr}$ doped leads to increase in the resistivity. The initial increase may be due to improved crystallinity and decrease in the grain size with increase in Cr concentration which in turn may affect the degree of carrier mobility. The electrical conductivity also increase with increase in measured temperature following the above trend.

\subsection{Sensing Characteristics}

The gas sensing response of undoped and doped $\mathrm{ZnO}$ film is shown in Figure 9(a) and Figure 9(b). It is a plot of change in electrical resistance of $\mathrm{ZnO}: \mathrm{Cr}$ thin film as a function of operating temperature for different concentration of $\mathrm{Cr}$ for a fixed concentration of ammonium in the gas chamber. Figure 9(a) and Figure 9(b) show that addition of $\mathrm{Cr}$ as a dopant enhanced the gas sensing response of the $\mathrm{ZnO}$ thin films. While Figure 9 (b) revealed that the optimum operating temperature is around $200^{\circ} \mathrm{C}$ irrespective of the doping concentration. At higher temperatures, the electrical resistance shows no significant variation with $\mathrm{Cr}$ doping concentration. This may be attributed to electrical stabilization of the surface with increase in $\mathrm{Cr}$ content and operating temperature which 
result in saturation of the surface thereby limiting the absorption-desorption reactions.

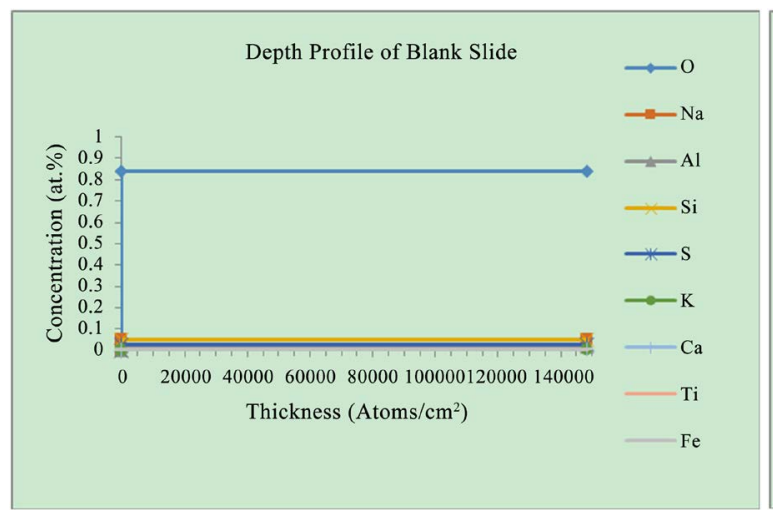

(a)

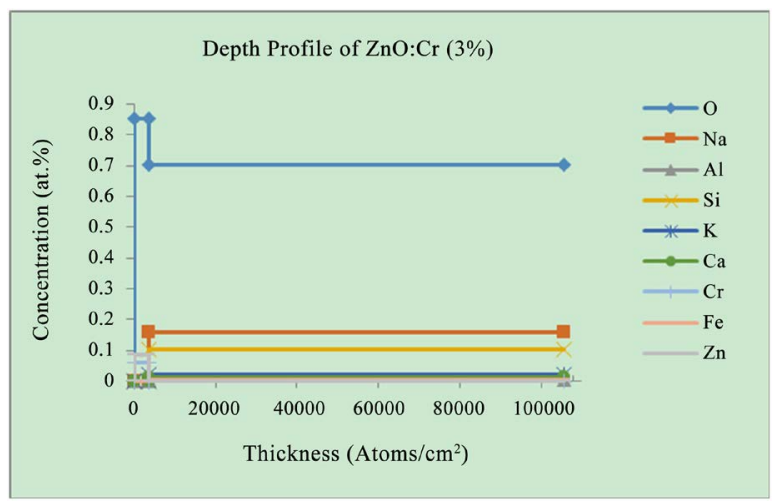

(c)

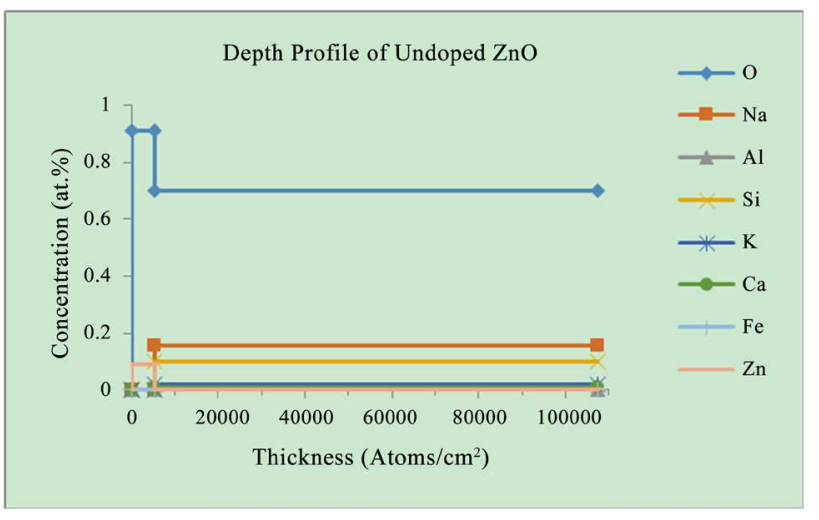

(b)

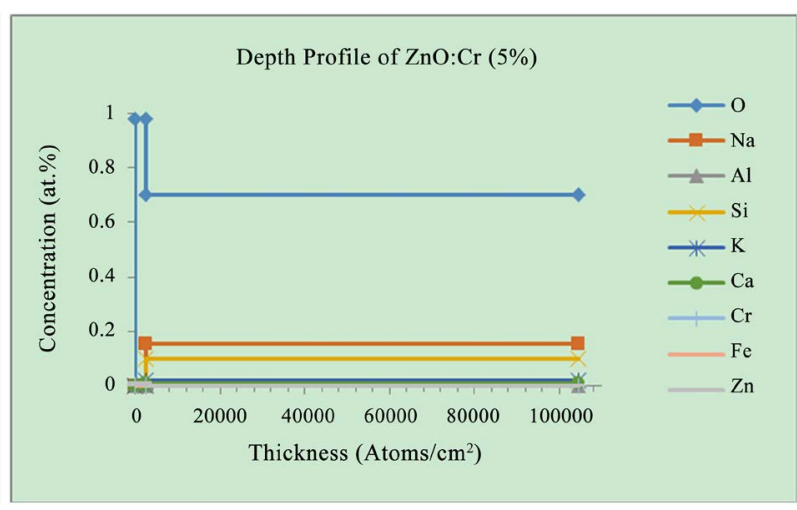

(d)

Figure 6. (a) Depth profile of Blank Slide substrate; (b) Depth profile of Undoped ZnO film; (c) Depth profile of 3\% Cr doped $\mathrm{ZnO}$ film; (d) Depth profile of 5\% Cr doped $\mathrm{ZnO}$ film.
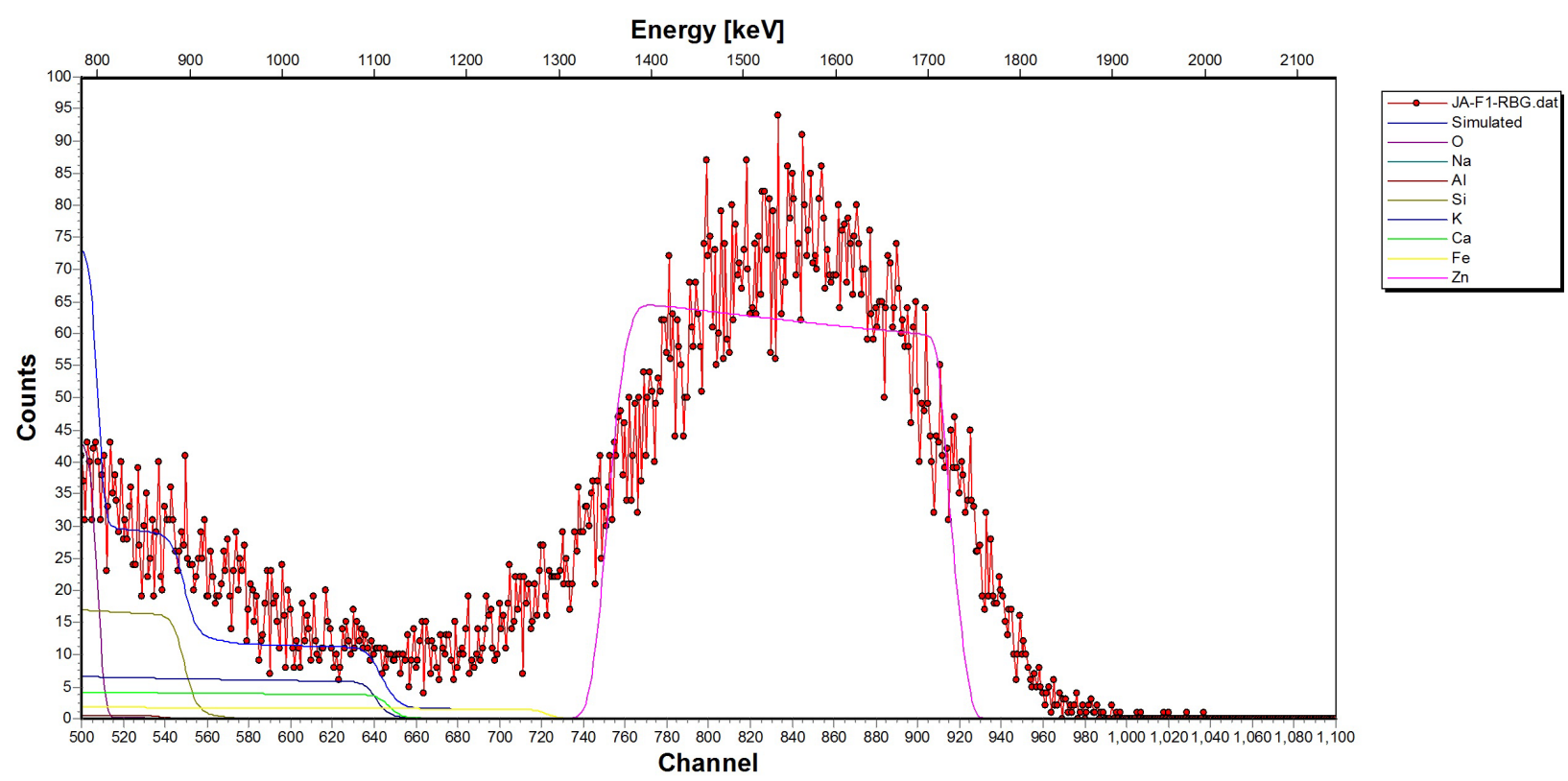

(a) 

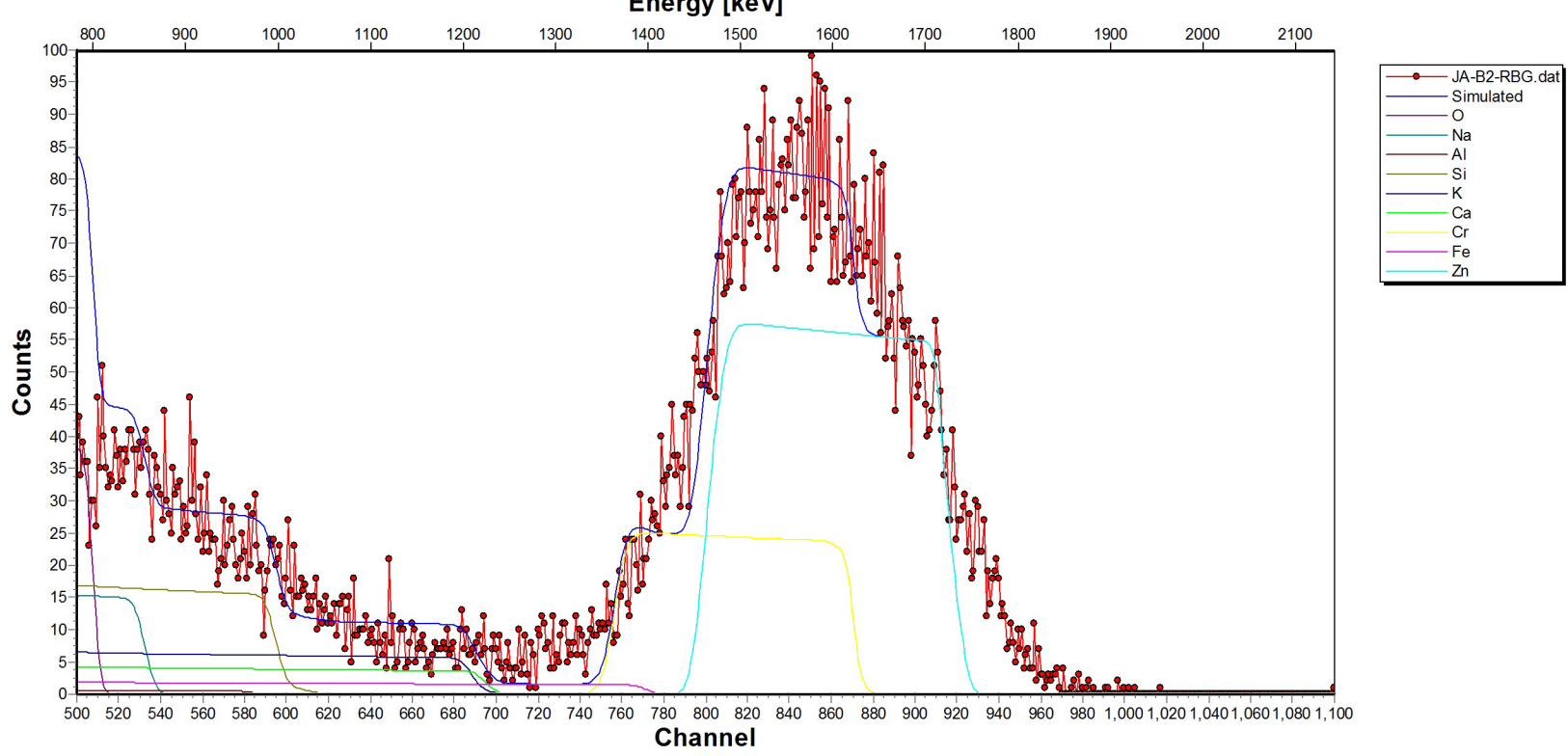

(b)

Figure 7. (a) RBS spectrum of the Undoped $\mathrm{ZnO}$ thin film; (b) RBS spectrum of the $3 \% \mathrm{Cr}$ doped $\mathrm{ZnO}$ thin film.

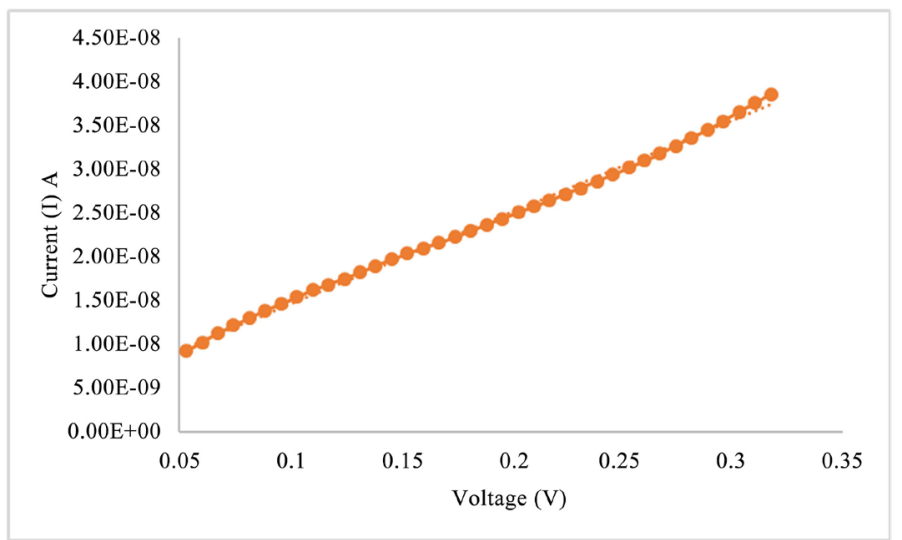

(a)

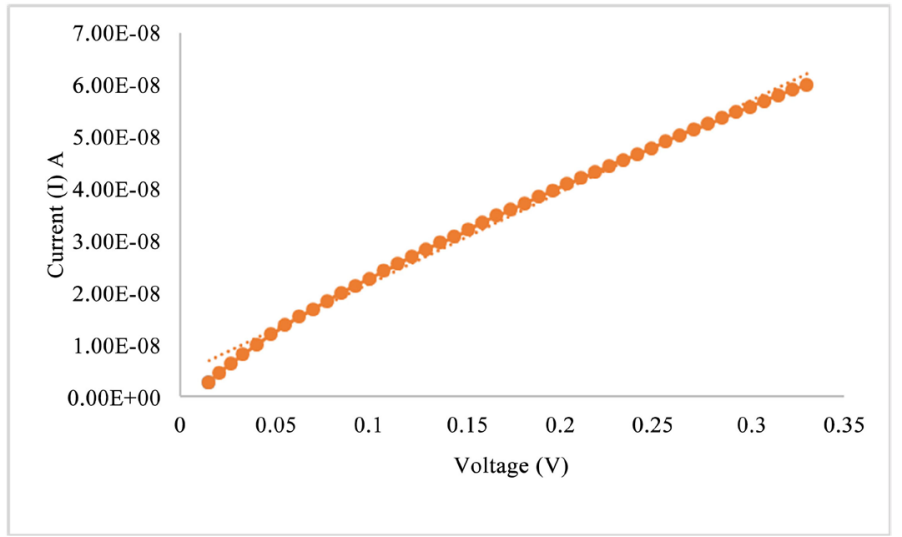

(a)

Figure 8. (a) I-V Characteristic of Undoped $\mathrm{ZnO}$; (b) I-V Characteristic of $3 \% \mathrm{Cr}$ doped $\mathrm{ZnO}$. 


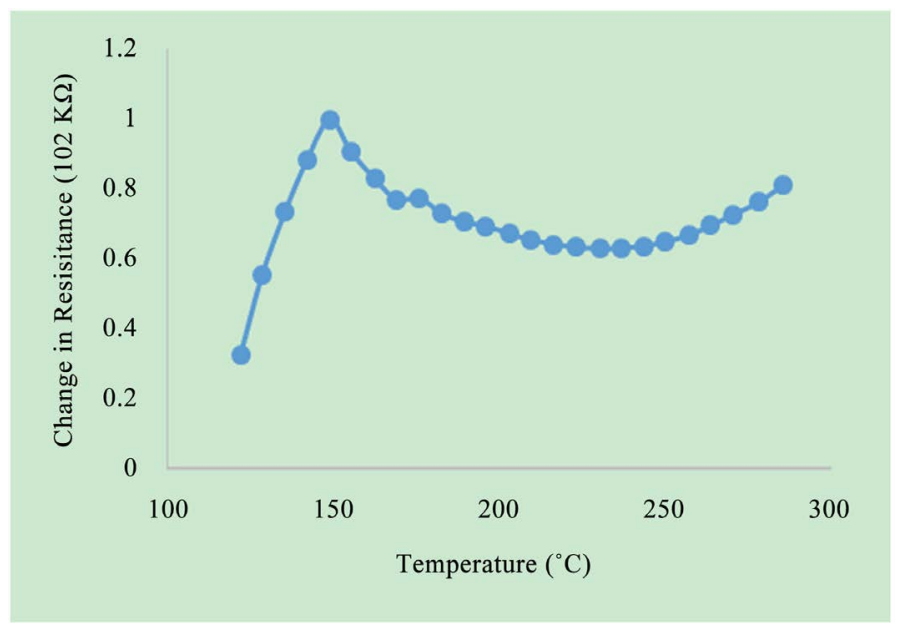

(a)

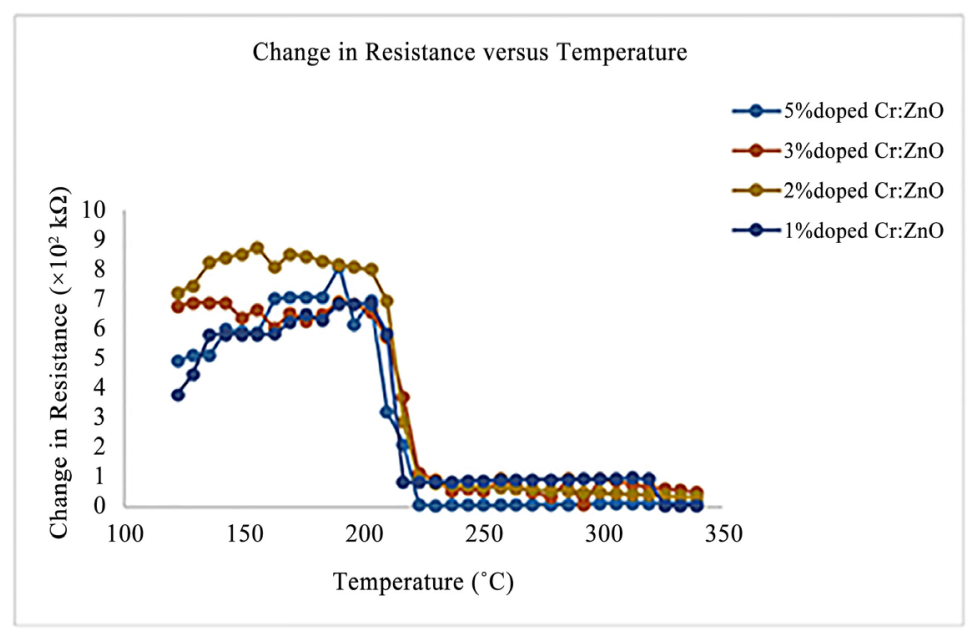

(b)

Figure 9. (a) Change in resistance against Temperature in the gas chamber for undoped $\mathrm{ZnO}$; (b) Change in resistance against Temperature in the gas chamber for $\mathrm{Cr}: \mathrm{ZnO}$.

\section{Conclusions}

Chromium (Cr) doped Zinc Oxide $(\mathrm{ZnO})$ thin films were grown on glass substrates using MOCVD technique. The effect of the chromium concentration on morphological, structural, optical, electrical and gas sensing properties of the films was investigated.

The morphological, optical and electrical studies revealed that the properties of the films depend on the $\mathrm{Cr}$ doping concentration and measuring temperature. RBS analysis also demonstrates that $\mathrm{Cr}$ ions are substitutionally incorporated into $\mathrm{ZnO}$. The gas sensing response of the films was enhanced with incorporation of $\mathrm{Cr}$ as a dopant with optimum operating temperature around $200^{\circ} \mathrm{C}$.

\section{Conflicts of Interest}

The authors declare no conflicts of interest regarding the publication of this paper. 


\section{References}

[1] Shinde, V.R., Gujar, T.P. and Lokhande, C.D. (2007) LPG Sensing Properties of ZnO Films Prepared by Spray Pyrolysis Method: Effect of Molarity of Precursor Solution. Journal of Sensors and Actuators B: Chemical, 120, 551-559. https://doi.org/10.1016/j.snb.2006.03.007

[2] Look, D.C. (2001) Recent Advances in ZnO Materials and Devices. Materials Science and Engineering B, 80, 383-387. https://doi.org/10.1016/S0921-5107(00)00604-8

[3] Jin, W., Lee, I.-K., Kompch, A., Dörfler, U. and Winterer, M. (2007) Chemical Vapor Synthesis and Characterization of Chromium Doped Zinc Oxide Nanoparticles. Journal of European Ceramic Society, 27, 4333-4337. https://doi.org/10.1016/j.jeurceramsoc.2007.02.152

[4] Arshak, K., Corcoran, J. and Korostynska, O. (2007) Gamma Radiation Sensing Properties of $\mathrm{TiO}_{2}, \mathrm{ZnO}, \mathrm{CuO}$ and $\mathrm{CdO}$ Thick Film pn-Junctions. Journal of Sensors and Actuators A: Physical, 123-124, 194-198. https://doi.org/10.1016/j.sna.2005.01.014

[5] Arora, A., Dwivedi, V.K., George, P.J., Sreenivas, K. and Gupta, V. (2008) Zinc Oxide Thin Film Based MEMS Acoustic Sensor with Tunnel for Pressure. Sensors and Actuators A: Physical, 141, 256.

[6] Granqvist, C.G. (2017) Transparent Conductors as Solar Energy Materials: A Panoramic Review. Solar Energy Materials and Solar Cell, 91, 1529-1598. https://doi.org/10.1016/j.solmat.2007.04.031

[7] Sun, M., Zhang, Q.F. and Wu, J.L. (2007) Electrical and Electroluminescence Properties of As-Doped p-Type ZnO Nanorod Arrays. Journal of Physics D: Applied Physics, 40, 3798-3802. https://doi.org/10.1088/0022-3727/40/12/036

[8] Xu, C.K., Chun, J., Kim, D.E., Kim, J.J., Chon, B. and Joo, T. (2007) Electrical Properties and near Band Edge Emission of Bi-Doped ZnO Nanowires. Applied Physics Letters, 90, Article ID: 083113.

[9] Zhang, H., Yang, D., Ma, X., Du, N., Wu, J. and Que, D. (2006) Straight and Thin ZnO Nanorods: Hectogram-Scale Synthesis at Low Temperature and Cathodoluminescence. Journal of Physical Chemistry B, 110, 827-830. https://doi.org/10.1021/jp055351k

[10] Senthilkumaar, S., Rajendran, K., Banerjee, S., Chini, T.K. and Sengodan, V. (2008) Influence of Mn Doping on the Microstructure and Optical Property of ZnO. Materials Science in Semiconductor Processing, 11, 6-12. https://doi.org/10.1016/j.mssp.2008.04.005

[11] Liu, Y., Yang, J.H., Guan, Q.F., Yang, L.L., Zhang, Y.J., Wang, Y.X., Feng, B., Cao, J., Liu, X.Y., Yang, Y.T. and Wei, M.B. (2009) Effects of Cr-Doping on the Optical and Magnetic Properties in ZnO Nanoparticles Prepared by sol-Gel Method. Journal of Alloys and Compounds, 486, 835-838.

[12] de la L. Olvera, M., Maldonado, A., Asomoza, R. and Mele'ndez-Lira, M. (2000) Chemical Stability of Doped ZnO Thin Films. Journal of Materials Science: Materials in Electronics, 11, 1-5. https://doi.org/10.1023/A:1008973800554

[13] Ramani, R.V., Ramani, B.M., Saparia, A.D., Savaliya, C., Rathod, K.N. and Markna, J.H. (2016) Cr-ZnO Nanostructured Thin Film Coating on Borosilicate Glass by Cost Effective Sol-Gel Dip Coating Method. Ain Shams Engineering Journal.

[14] Elanchezhiyan, J., Bhuvana, K.P., Gopalakrishnan, N., Chang, Y., Sivananthan, S., Senthil Kumar, M. and Balasubramanian, T. (2009) Realization of Room Temperature Ferromagnetism in $\mathrm{Zn}_{1-x} \mathrm{Cr}_{x} \mathrm{O}$ Thin Films Grown by RF Magnetron Sputtering. 
Journal of Alloys and Compounds, 468, 7-10.

[15] Hu, Y.M., Chen, Y.T., Zhong, Z.X., Yu, C.C. and Wang, C.R. (2008) The Morphology and Optical Properties of Cr-Doped ZnO Films Grown Using the Magnetron Co-Sputtering Method. Applied Surface Science, 254, 3873-3878.

[16] Shinoda, M., Nishide, T., Sawada, Y., Hosaka, M. and Matsumoto, T. (1993) Stability of Sputter Deposited Chromium-Doped Zinc Oxide $(\mathrm{ZnO})$ Films against Acids. Japanese Journal of Applied Physics, Part 2: Letters, 32, L1565-L1567. https://doi.org/10.1143/JJAP.32.L1565

[17] Satoh, I. and Kobayashi, T. (2003) Magnetic and Optical Properties of Novel Magnetic Semiconductor Cr-Doped $\mathrm{ZnO}$ and Its Application to All Oxide p-i-n Diode. Journal of Applied Surface Science, 216, 603-606.

[18] Iqbal, A., Mahmood, A., Khan, T.M. and Ahmed, E. (2013) Structural and Optical Properties of Cr Doped ZnO Crystalline Thin Films Deposited by Reactive Electron Beam Evaporation Technique. Progress in Natural Science: Materials International, 23, 64-69. https://doi.org/10.1016/j.pnsc.2013.01.010

[19] Aguilar-Leyva, J., Maldonado, A. and de la Olvera, M.L. (2007) Gas-Sensing Characteristics of Undoped-SnO ${ }_{2}$ Thin Films and $\mathrm{Ag} / \mathrm{SnO}_{2}$ and $\mathrm{SnO}_{2} / \mathrm{Ag}$ Structures in a Propane Atmosphere. Materials Characterization, 58, 740-744. https://doi.org/10.1016/j.matchar.2006.11.016

[20] Maldonado, A., Mallen-Hernandez, S.A., Vega-Perez, J., de la Olvera, M.L. and Tirado-Guerra, S. (2009) Chromium Doped Zinc Oxide Thin Films Deposited by Chemical Spray Used in Photo-Catalysis and Gas Sensing. Revista Mexicana de Fisica, 55, 90-94.

[21] Khoza, P.B., Moloto, M.J. and Sikhwivhilu, L.M. (2012) The Effect of Solvents, Acetone, Water, and Ethanol, on the Morphological and Optical Properties of $\mathrm{ZnO}$ Nanoparticles Prepared by Microwave. Journal of Nanotechnology, 2012, Article ID: 195106.

[22] Lucio-Lopez, M.A., Luna-Arias, M.A., Maldonado, A. and de la Olvera, M.L. (2006) Chromium Doped Zinc Oxide Thin Films Deposited by Chemical Spray Used in Photo-Catalysis and Gas Sensing. Revista Mexicana de Fisica, 55, 90-94.

[23] Jayaraman, V.K., Álvarez, A.M., Bizarro, M., Koudriavtsev, Y. and de la Luz Olvera Amador, M. (2017) Effect of Precursor Type and Doping Concentration on the Physical Properties of Ultrasonically Sprayed Aluminium and Indium Co-Doped Zinc Oxide Thin Films. Thin Solid Films, 642, 14-19. https://doi.org/10.1016/j.tsf.2017.09.012

[24] Fitzgerald, C.B., Venkatesan, M., Lunney, J.G., Dorneles, L.S. and Coey, J.M.D. (2005) Cobalt-Doped ZnO-A Room Temperature Dilute Magnetic Semiconductor. Applied Surface Science, 247, 493-496. https://doi.org/10.1016/j.apsusc.2005.01.043

[25] Bylsma, R.B., Becker, W.M., Kossut, J., Debska, U. and Yoder-Short, D. (1986) Dependence of Energy Gap on $x$ and $T$ in $\mathrm{Zn}_{1-\mathrm{x}} \mathrm{Mn}_{\mathrm{x}} \mathrm{Se}$ : The Role of Exchange Interaction. Physical Review B, 33, 8207-8215. https://doi.org/10.1103/PhysRevB.33.8207

[26] Lee, Y.R., Ramdas, A.K. and Aggarwal, R.L. (1988) Energy Gap, Excitonic, and "Internal" $\mathrm{Mn}^{2+}$ Optical Transition in Mn-Based II-VI Diluted Magnetic Semiconductors. Physical Review B, Condensed Matter, 38, 10600-10610.

[27] Gomez, H., Maldonado, A., Casatanedo-perez, R., Torres-Delgado, G., de La, M. and Olvera, L. (2007) Properties of Al-Doped ZnO Thin Films Deposited by a Chemical Spray Process. Materials Characterization, 58, 708-714.

https://doi.org/10.1016/j.matchar.2006.11.012 